\title{
Antenatal and postnatal management of posterior urethral valves: where do we stand?
}

\author{
Ahmed Abdelhalim* ${ }^{*}$ and Ashraf T. Hafez
}

\begin{abstract}
Introduction: Posterior urethral valve (PUV) is the leading etiology of lower urinary tract obstruction (LUTO) in boys and is an important cause of end-stage renal disease (ESRD) in children. The aim of this article is to review the current status on antenatal intervention for PUV as well as postnatal medical and surgical management.

Main body: MEDLINE, EMBASE, Pubmed and Google Scholar search was conducted throughout December 2020 using the keywords: posterior urethral valves, congenital urinary obstruction, antenatal, valve bladder syndrome, medical, anticholinergics, alpha blocker, antibiotics, biofeedback, diversion, augmentation cystoplasty and renal transplantation. Only papers written in English were included. The relevant literature was summarized. Despite advances in antenatal intervention for fetal LUTO, it remains associated with considerable fetal and maternal morbidity. Patient selection criteria for antenatal intervention are greatly debated. Fetal intervention has resulted in improved perinatal survival in properly selected cases, with a questionable benefit to postnatal renal function. There is decent evidence supporting the use of anticholinergics in infants and young children following valve ablation, with less robust evidence advocating alpha blockers, overnight catheter drainage and biofeedback. The role of urinary diversion remains contentious. Optimizing bladder dynamics is crucial for successful renal transplantation outcomes.
\end{abstract}

Conclusion: While antenatal intervention has failed to improve renal function outcomes of PUV, patient-centered medical and sometimes surgical interventions can help delay the progression of chronic kidney disease. Lifelong monitoring and management of the associated bladder dysfunction is indispensable even after successful renal transplantation.

Keywords: Posterior urethral valve, Antenatal, Medical, Anticholinergic, Diversion, Bladder neck incision, Bladder augmentation, Kidney transplantation

\section{Background}

Posterior urethral valve (PUV) is the most common cause of lower urinary tract obstruction (LUTO) in children and is an important etiology of end-stage renal disease (ESRD) in children. Consequent to LUTO, a cascade of structural and functional changes affects the developing bladder leading to bladder dysfunction (BD) in a significant patient proportion even after successful relief of obstruction. The resulting BD puts the upper tract at risk if not properly addressed [1]. Except for miniaturization

*Correspondence: a_halim_2010@yahoo.com

The Department of Urology, Mansoura Urology and Nephrology Center,

Mansoura University, Gomhoria Street, Mansoura 35516, Egypt of surgical endoscopes and the use of laser technology for valve ablation, little advances have been achieved in the primary postnatal surgical management of PUV. Meanwhile, a huge leap has been accomplished in the field of antenatal diagnosis and intervention of fetuses diagnosed with LUTO [2]. Also, BD in boys with PUV, commonly known as "the valve bladder syndrome," has been extensively investigated by a myriad of studies. Deep understanding of the urodynamic consequences of PUV has introduced new modalities for medical management of valve bladder syndrome with subsequently improved upper tract and continence outcomes. It has also narrowed the scope of surgical reconstruction to those who continue to deteriorate despite maximal management. 
In this manuscript, we aim to summarize the advances achieved in the field of antenatal intervention for prenatally suspected PUV and review medical management of valve bladder syndrome. Further, an update on some surgical aspects of PUV, including techniques of valve ablation, urinary diversion, augmentation cystoplasty (AC) and renal transplantation (RT), is briefly presented.

\section{Main text}

\subsection{Materials and methods}

The authors systematically searched MEDLINE, EMBASE, Pubmed and Google Scholar through December 2020 using a combination of the keywords: posterior urethral valves, congenital urinary obstruction, antenatal, valve bladder syndrome, medical, anticholinergics, alpha blocker, antibiotics and biofeedback, diversion, augmentation cystoplasty, renal transplantation and their word variants. Titles and abstracts were carefully reviewed to identify articles of interest. The reference lists of the articles obtained were also searched for any relevant articles. Only papers written in English were reviewed. Case reports and case series were excluded. The review mainly focused on meta-analyses, reviews, randomized controlled trails if available and cohort studies. In case of multiple publications from the same institution, we have included the most recent study or the one with the largest number of subjects. This literature was summarized in the manuscript.

\section{Results}

A total of 477 articles met the search criteria. We primarily aimed at focusing on meta-analyses, systematic reviews, randomized controlled trials if available and cohort studies. Case reports were excluded. In case of duplicate publication, the most recent version was selected. A total of 129 articles were carefully reviewed, the full text of which was obtained. The number was reduced to 96 in an effort to include studies with the better quality or larger patient population. The flowchart of the search process is shown in Fig. 1. The data retrieved were summarized in the current review.

\section{Discussion}

\section{I.Antenatal diagnosis and intervention for PUV:}

\section{- Antenatal diagnosis:}

With widespread use of prenatal ultrasound, $46-53 \%$ of PUV cases are suspected antenatally [3]. Prenatal ultrasound findings of bilateral hydroureteronephrosis, megacystis and dilation of the posterior urethra (the keyhole sign) with or without oligohydramnios in a male fetus are suggestive, but not specific for PUV. Prenatal ultrasound diagnosis of PUV was reported to be $94 \%$ sensitive, but

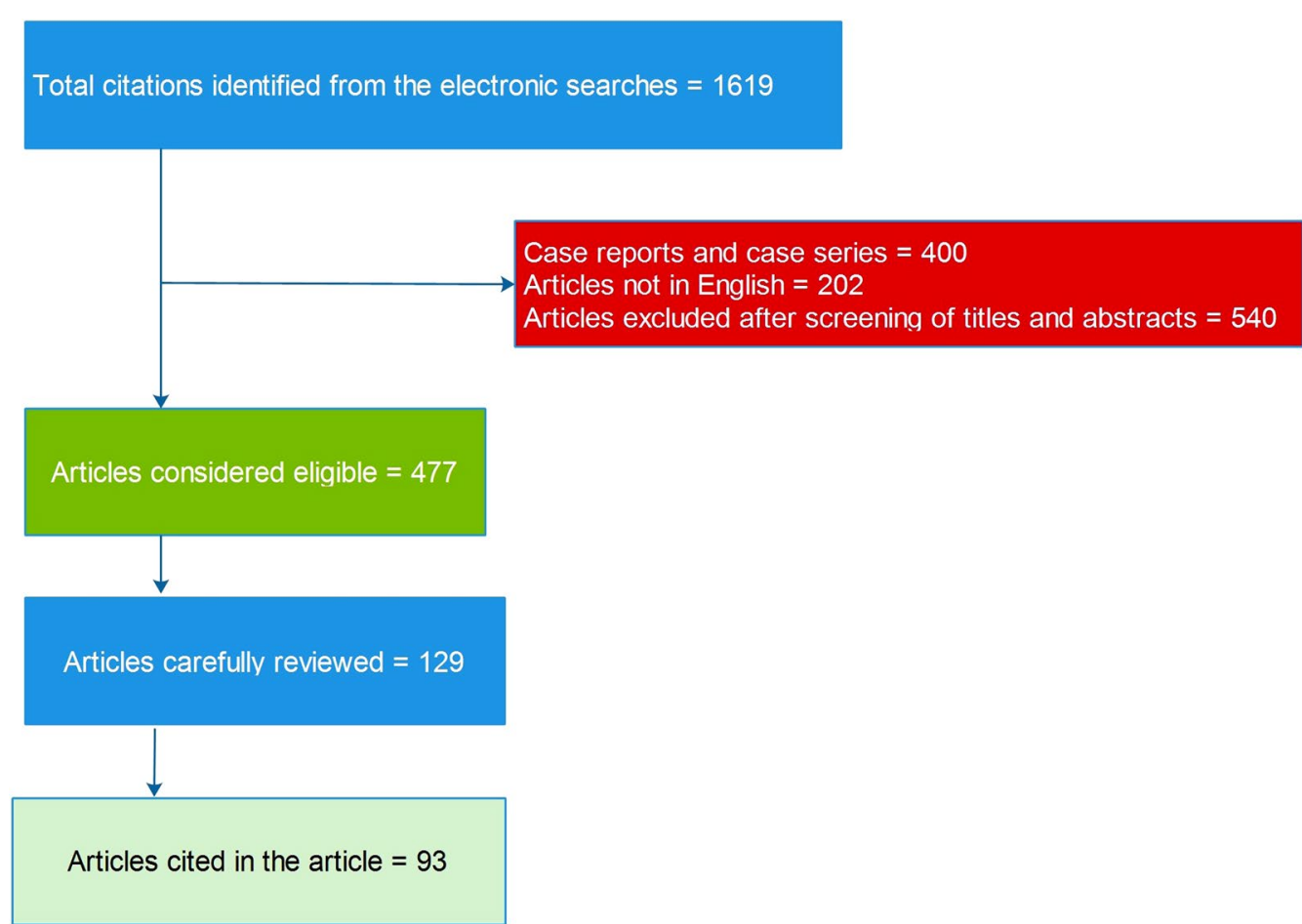

Fig. 1 Flowchart of the search process 
only $43 \%$ specific. The low specificity of prenatal ultrasound diagnosis reflects its poor ability in distinguishing PUV from other causes of fetal LUTO including urethral atresia and prune belly syndrome [4]. Maternal obesity, unfavorable fetal position and oligohydramnios further limit the ability of antenatal ultrasound in delineating fetal urinary tract anomalies $[5,6]$.

Compared to antenatal ultrasound, fetal MRI provides superior anatomic details and better assessment of the ureteral and posterior urethral dilation without being significantly affected by the amniotic fluid volume or fetal position (Fig. 2). Therefore, fetal MRI can more reliably distinguish PUV from other etiologies of antenatal hydronephrosis. Pico et al. reported that fetal MRI findings coincided with the postnatal diagnosis of urinary tract anomalies in $97 \%$ of cases, relative to $56 \%$ with ultrasound examination alone and changed the perinatal care in $15 \%$ of patients included in that study [7]. Faure et al. found that a higher-than-normal apparent diffusion coefficient (ADC) of the renal parenchyma on fetal DWMRI was associated with unfavorable postnatal outcome. In their study of 11 fetuses with the prenatal diagnosis of PUV, two cases with oligohydramnios, hyperintense kidneys and significantly elevated $\mathrm{ADC}$ were terminated. All four live-born fetuses with elevated ADC (1.8-2.3 $\mathrm{mm}^{2} / \mathrm{s}$, normal range $1.2-1.8 \mathrm{~mm}^{2} / \mathrm{s}$ ) had severe pulmonary hypoplasia, suffered respiratory distress at birth and developed renal insufficiency later in life. They suggested that ADC of the renal parenchyma can help in parental counseling and decision making for prenatal intervention [8]. Like prenatal ultrasound, fetal MRI is not without limitations. Some centers recommend performing fetal MRI between 28 and 32 weeks of gestation to enhance image quality. By that time, irreversible fetal renal damage may have already taken place, limiting the usefulness of antenatal intervention. Maternal sedation is required
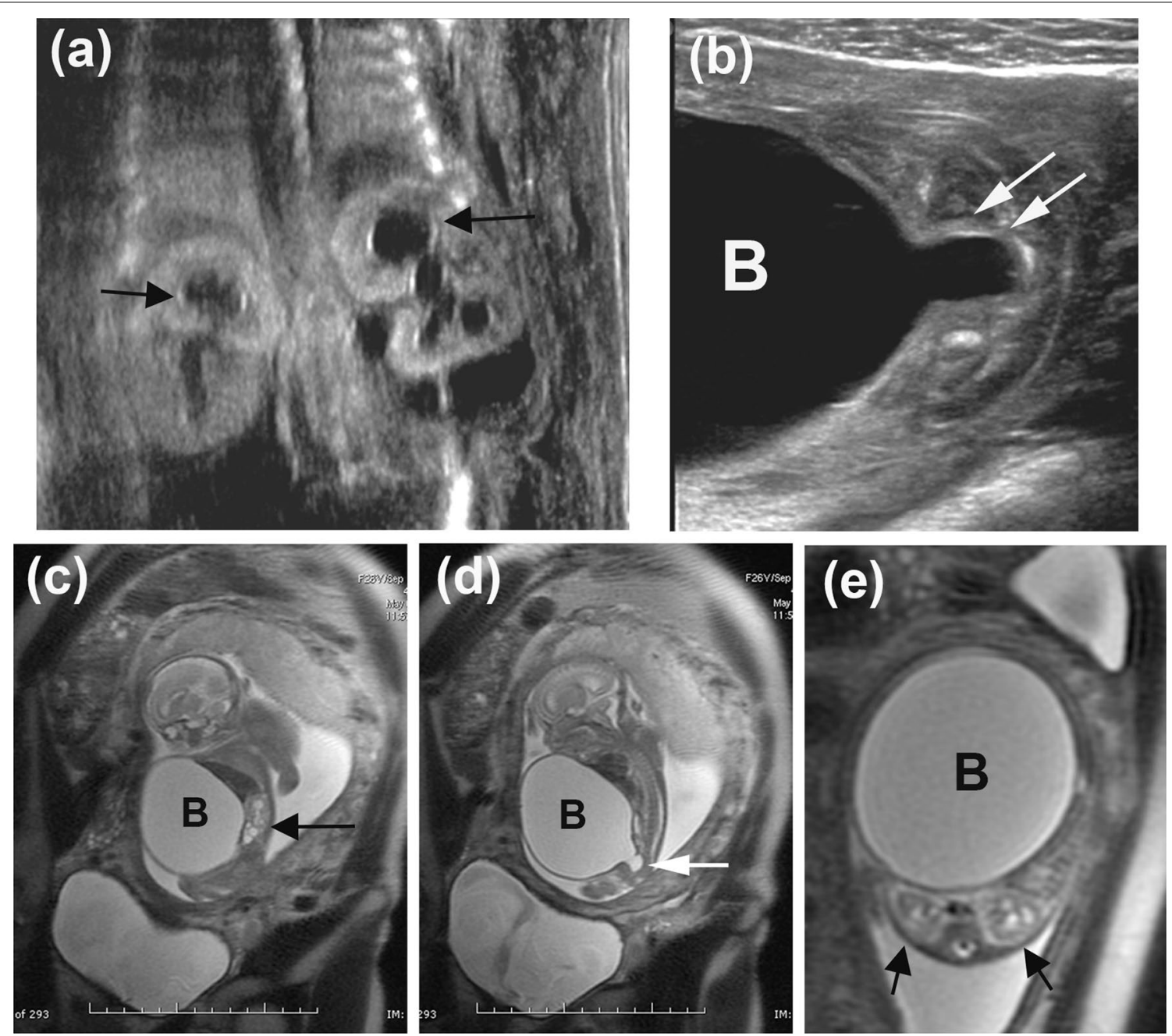

Fig. 2 Prenatal ultrasound $\mathbf{a}, \mathbf{b}$ and fetal MRI c, d , e showing bilateral hydronephrosis (black arrows), distended bladder (B) with dilation of the posterior urethra "the keyhole sign" (white arrows), suggestive of the diagnosis of posterior urethral valve 
by some protocols for fetal MRI to limit fetal movements and enhance image quality. Further, fetal MRI is still not widely available and its interpretation requires special expertise. The role of fetal cystoscopy in confirming the diagnosis of PUV will be discussed later in the manuscript. The management of antenatally diagnosed PUV is summarized in Fig. 3.

\section{- Patient selection for antenatal intervention:}

Untreated fetal LUTO carries a perinatal mortality rate in the range of $45 \%$ that rises to $95 \%$ in the presence of mid-trimester oligohydramnios [2, 6]. Furthermore, ESRD develops in $25-44 \%$ of survivors during childhood $[2,3]$. The devastating consequences of fetal LUTO have driven enthusiasm in antenatal intervention. Because of its significant maternal and fetal morbidity, careful selection of candidates for fetal bladder drainage is of utmost importance and is probably the most challenging conundrum of antenatal intervention. For years, fetal urine biochemical characteristics have been used to triage fetuses for antenatal intervention. Fetal bladder urinary sodium $>100 \mathrm{mEq} / \mathrm{L}$, chloride $>90 \mathrm{mEq} / \mathrm{L}$ and osmolarity $>210 \mathrm{mOsm} / \mathrm{L}$ were considered indicative of poor renal function outcome. Sequential measurements that are trending toward normal are indicative of good fetal renal function and are generally considered more reliable than a single measurement [9-11]. Nicolini et al. suggested two fetal bladder aspirations on two consecutive days [12], whereas Freedman et al. recommended at least 3 aspirations $48-72 \mathrm{~h}$ apart [13]. Some investigators used a fetal urinary 32 -microglobulin of $>6 \mathrm{mg} / \mathrm{L}$ and a fetal serum $ß 2$-microglobulin $\geq 5 \mathrm{mg} / \mathrm{L}$ as predictors of poor postnatal renal function. Fetal urinary B2-microglobulin level higher than $13 \mathrm{mg} / \mathrm{L}$ is considered invariably lethal and is used as an indication for termination of pregnancy [10, 14]. Changes of the fetal serum B2-microgloulin following antenatal intervention can reflect the recoverability of fetal renal function, unlike changes of the fetal urinary electrolytes and B2-microgloulin as shown by Craparo and coworkers [15]. According to a systematic review by Morris et al., fetal urinary calcium $>95^{\text {th }}$ centile [positive $\mathrm{LR}=6.65(0.23-190.96)$; negative $\mathrm{LR}=0.19(0.05$ $0.74)$ ] and sodium $>95^{\text {th }}$ centile for gestation [positive $\mathrm{LR}=4.46(1.71-11.6)$; negative $\mathrm{LR}=0.39(0.17-0.88)]$ are

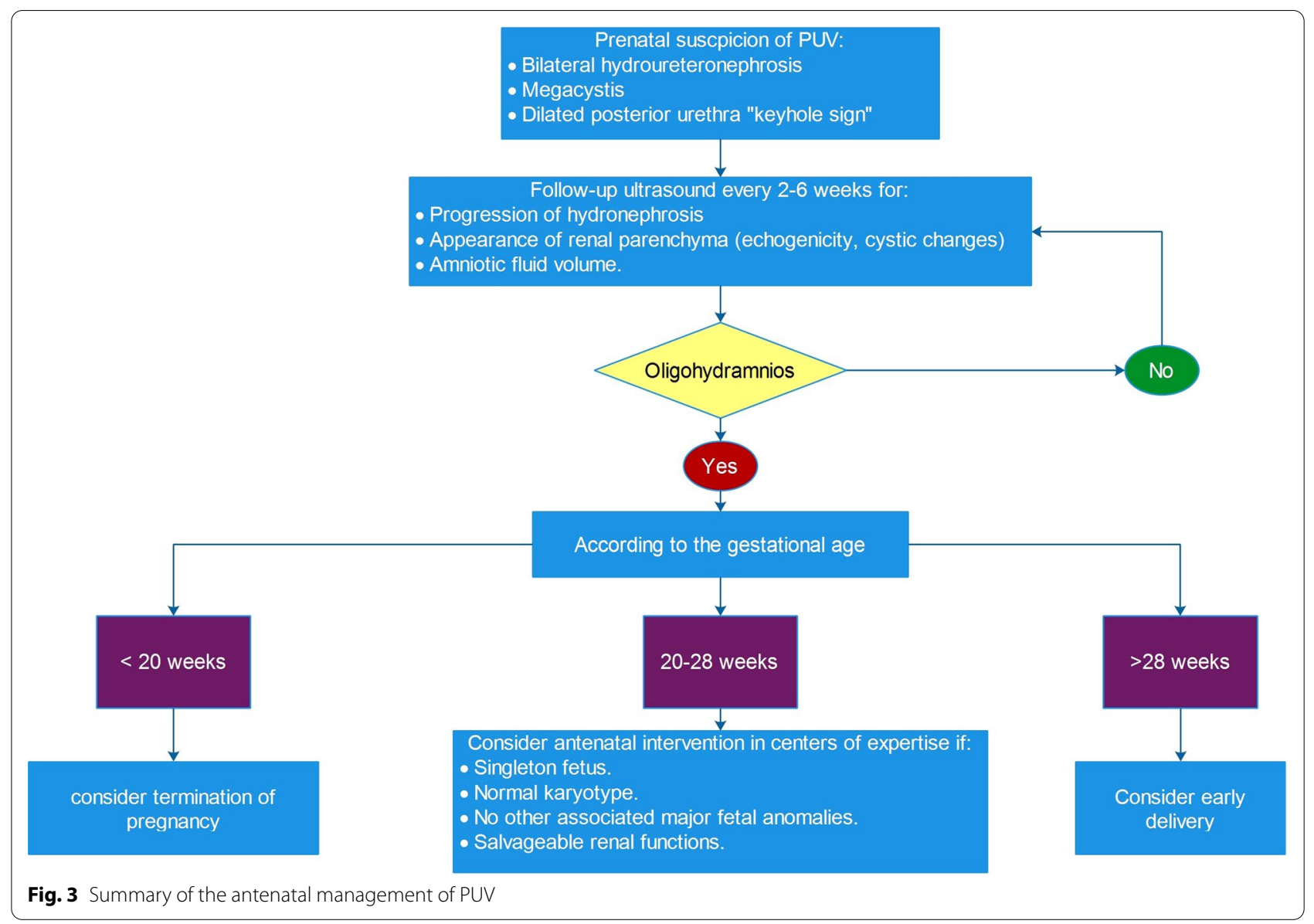


the most accurate fetal urinary predictors of poor postnatal renal function. Other urinary analytes (e.g., IGF-1, creatinine and cystatin C) have also been used less frequently. Despite their wide use, fetal urinary analytes have limited overall accuracy with a sensitivity in the range of $40-100 \%$ and a specificity not exceeding $80 \%$. Therefore, it should be cautiously interpreted when used to select patients for antenatal intervention [16].

Fetal urinary proteomics have also been used to predict postnatal renal function and outperformed other predictors of early postnatal ESRD with an $88 \%$ sensitivity and 95\% specificity. Combining fetal urinary metabolomics with proteomics significantly improved the diagnostic accuracy of fetal metabolomics, but not that of the fetal proteomics [17]. Yet, these promising tools are neither widely available nor routinely used.

To avoid the invasive nature and significant morbidity associated with fetal urine or blood sampling, some radiologic features (including gestational age at diagnosis, amniotic fluid volume, megacystis, severity of hydronephrosis and the appearance of the renal cortex) were used to predict postnatal renal function. Ultrasonic appearance of the renal cortex (hyperechogenic or cystic) was considered the most accurate ultrasound predictor (sensitivity $57 \%$, specificity $84 \%$ ) of poor postnatal function in a meta-analysis by Morris et al. [18]. As mentioned earlier, Faure et al. suggested that ADC of the fetal renal parenchyma on diffusion-weighted fetal MRI can predict postnatal renal function [8]. Table 1 summarizes the advantages, disadvantages and diagnostic performance of fetal parameters used to select patients for antenatal intervention.

\section{- Techniques and outcomes of antenatal interven- tion for fetal LUTO:}

Antenatal intervention for severe LUTO, by means of vesicoamniotic shunting (VAS) or fetoscopic valve ablation (FVA), aims at preventing further renal damage, reversing oligohydramnios and allowing more normal bladder and lung development. Antenatal intervention is typically offered between 20 and 28 weeks of gestation, but has been performed as early as 12.3 weeks[19]. Given its associated significant perinatal morbidity and mortality, antenatal intervention is typically reserved for singleton, male fetuses with normal karyotyping, no other associated major anomalies, presumably salvageable renal functions and potentially fatal LUTO resulting in late first or early second trimester oligohydramnios. The small number of cases, significant variability of the thresholds used for patient selection and non-uniform outcome measures are obvious limitations to most studies addressing antenatal therapy.
Open fetal surgery to relieve fetal LUTO with cutaneous vesicostomy or bilateral ureterostomies has been largely abandoned and replaced by the less morbid VAS and FVA [2]. Several studies have demonstrated the feasibility of VAS, yet with controversial benefit to perinatal survival and postnatal renal function $[9,11,13]$. PLUTO (percutaneous intervention for fetal LUTO) is the only available randomized multicenter trial comparing VAS and conservative management of fetal LUTO. Although VAS was associated with improved neonatal survival over conservative management in that trial, VAS failed to prevent or at least reduce the incidence of ESRD. Despite the significant technical refinements including: amnioinfusion to improve visualization, temporary fetal paralysis and improved imaging techniques with more accurate catheter placement, significant perinatal morbidity and mortality occurred in $40 \%$ of cases treated with VAS. When reviewing the results of PLUTO trial, two issues should be kept in mind. First, the study was planned to include 75 pregnant ladies in each arm, but it was closed prematurely with only 31 cases enrolled in both arms due to poor patient recruitment. Therefore, the study could be under-powered. Secondly, of all the study subjects only two infants survived to the age of 2 years with normal renal function denoting poor overall postnatal renal function outcome irrespective of the treatment approach [6]. In a meta-analysis including 112 fetuses who were shunted and 134 fetuses treated conservatively, VAS was associated with a statistically better survival in the first 6 months of life (57\% for VAS vs. 39\% for observation). However, shunting neither impacted survival between 6 and 12 months nor improved postnatal renal function. Interestingly, the effect of shunting was less obvious in patients with favorable fetal urinary analytes [20]. Likewise, Ruano reported better survival after VAS shunting and proposed a classification to assess the severity of fetal LUTO and select patients for antenatal intervention [21].

Fetal cystoscopic valve ablation was later introduced with several potential advantages over VAS. Fetal cystoscopy enables endoscopic examination of the bladder and proximal urethra to confirm the diagnosis of PUV and exclude other etiologies of LUTO. FVA also allows more definitive and physiologic relief of obstruction without compromising fetal bladder cycling. Additionally, it avoids the mechanical complications associated with VAS including shunt tube obstruction or dislodgement with the subsequent need for reintervention. Another advantage of FVA is the avoidance of amnioinfusion with its well-known risks [22]. More importantly, there is some evidence that FVA may improve renal function outcome compared to conservative management or VAS. In a multicenter study of 111 pregnancies complicated by fetal LUTO with oligo- or an-hydramnios, 61 


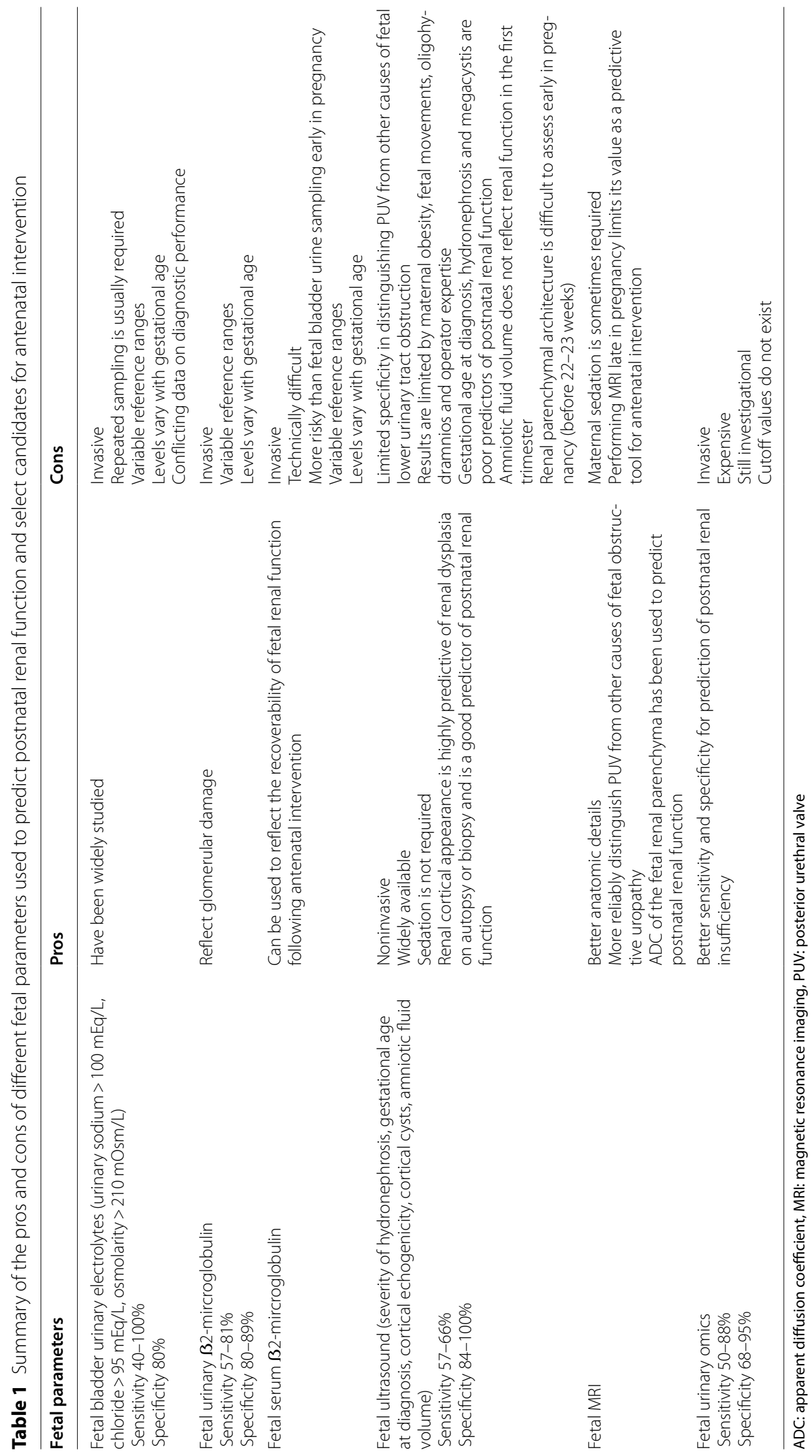


patients were treated expectantly, 34 underwent FVA, and 16 underwent VAS insertion. All three groups had favorable fetal urine biochemical parameters at baseline. Perinatal survival was higher in the fetal cystoscopy (38.2\%) and VAS (43.8\%), relative to the expectant management group (19.7\%). The 6-month survival rate was not statistically different between the FVA and VAS groups $(p=0.76)$, but the FVA group had a higher percentage of patients with normal postnatal renal function (75\%), compared to the expectant management group $(39.3 \%)(p=0.03)$. Such an effect was not seen in the VAS group $(p=0.29)$ [23]. Of course, FVA is more technically demanding and requires considerable expertise. In a series of 40 fetuses with LUTO treated with FVA, urinary fistula was the most common complication seen in $10 \%$. The associated complication rate was significantly lower when the procedure was performed by a more experienced fetal surgeon [24]. With any antenatal intervention technique, periodic surveillance is mandatory to monitor fetal viability, exclude LUTO recurrence and ensure restoration of the amniotic fluid volume. Reintervention may be considered in patients with unresolved or recurrent obstruction [23].

\section{- Limitations of antenatal intervention for PUV:}

Several constraints limit the use of antenatal intervention technique for fetal LUTO. First, ultrasonic features of LUTO are not specific for PUV. Second, the correct diagnosis can be impacted by gestational age, the skill of the obstetric sonographer and the amniotic fluid volume [4]. Third, studies on antenatal intervention are mostly small case series with heterogeneous patient population and several technical modifications within and between individual studies. Therefore, it is difficult to generalize the conclusions of these studies. There is no consensus on the ideal timing and patient selection criteria for antenatal intervention, as previously discussed. Further, antenatal intervention is associated with significant maternal and fetal morbidity, limiting its use to centers with profound expertise in fetal intervention and fetuses unlikely to survive without intervention. Moreover, repeated interventions may be required with shunt dislodgement or with recurrent signs of LUTO in subsequent followup. Although there is some evidence that antenatal intervention improves perinatal survival, there is not strong enough evidence to support its benefit to postnatal renal and bladder function. The results of some of the previous studies addressing antenatal intervention for fetal LUTO are summarized in Table $2[6,9-13,23,25,26]$.

\section{Medical treatment for PUV:}

Even after successful PUV ablation, persistent BD (a.k.a. valve bladder syndrome) is seen in $70-80 \%$ of patients [1, $27,28]$. Most infants and young children with PUV have reduced capacity, hypocompliant bladders with or without detrusor overactivity (DO). As those children grow, their bladder capacity and compliance gradually improve, but myogenic failure may take place [1]. These urodynamic observations formed the basis of management of valve bladder syndrome with the hope of improving bladder dynamics and subsequently continence and upper tract outcomes.

\section{- Anticholinergic treatment:}

The successful use of anticholinergics in patients with poorly compliant and overactive neurogenic bladders has led clinicians to consider their use in patients with PUV and similar urodynamic abnormalities. To date, oxybutynin is the only anticholinergic medication approved for use in children and has been used in children with PUV at dose of $0.1-0.2 \mathrm{mg} / \mathrm{kg}$ BID or TID [29]. Higher doses were given in older children up to $5 \mathrm{mg}$ times daily [30]. Oxybutynin treatment has also been tested in infants with PUV based on the assumption that early anticholinergic treatment could potentially hasten bladder recovery and decrease the risk of permanent bladder dysfunction [29]. The indications for oxybutynin treatment in that study were high voiding pressure $(>60 \mathrm{~cm} \mathrm{H} 2 \mathrm{O})$, small bladder capacity $(<70 \%$ of the expected bladder capacity for age) [29]. Other investigators used anticholinergic medications later in life for patients who demonstrated small capacity, impaired compliance or DO in the absence of bladder outlet obstruction [31,32].

Puri reported symptomatic improvement in 16 of 30 children with history of PUV, along with a concomitant increase in the cystometric capacity and lowered bladder pressures following treatment with imipramine, an antidepressant with known anticholinergic activity [31,32]. Casey et al., hypothesized that oxybutynin treatment in infants with PUV can promote bladder remodeling and reduce the risk of permanent $\mathrm{BD}$. In their study of 18 PUV infants with high voiding pressure and/or small bladder capacity, oxybutynin treatment for a mean of 2.2 years resulted in improved compliance in all patients with reduced compliance. Patients with reduced bladder capacity demonstrated an increase in the bladder capacity from a mean of $47.7 \%$ to $216 \%$ of expected bladder capacity for age [29]. In a randomized controlled study, 
Table 2 Study characteristics and outcomes of antenatal intervention for fetal lower urinary tract obstruction

\begin{tabular}{|c|c|c|c|c|}
\hline Study & Study design & Patient characteristics & Survival outcome & Renal function outcome \\
\hline Crombleholme 1990 [9] & Retrospective & $\begin{array}{l}40 \text { fetuses: } \\
16 \text { good prognosis group ( } 9 \\
\text { treated) } \\
24 \text { poor prognosis group ( } 10 \\
\text { treated) }\end{array}$ & $\begin{array}{l}\text { OS: } 38 \% \\
\text { After exclusion of elective } \\
\text { terminations: } 58 \% \text { OS } \\
\text { Good prognosis group: } 81 \% \\
\text { OS } \\
\text { Poor prognosis group: } 13 \% \\
\text { OS }\end{array}$ & $\begin{array}{l}\text { Good prognosis group: none of } \\
9 \text { treated survivors had ESRD } \\
\text { Poor prognosis group: } 2 / 3 \\
\text { treated survivors had ESRD }\end{array}$ \\
\hline Nicolini 1991 [12] & Retrospective & 17 fetuses (8 had VAS) & $\begin{array}{l}\text { Only } 2 \text { fetuses with VAS } \\
\text { survived }(25 \%) \\
\text { The remaining patients were } \\
\text { terminated, aborted or died } \\
\text { in the neonatal period }\end{array}$ & $\begin{array}{l}\text { The two survivors had normal } \\
\text { RF at follow-up }\end{array}$ \\
\hline Lipitz 1993 [10] & Retrospective & 25 fetuses (14 had VAS) & $\begin{array}{l}\text { VAS: } 6 / 14(43 \%) \text { survived the } \\
\text { neonatal period } \\
\text { No treatment: } 3 / 11(27 \%) \\
\text { survived the neonatal period }\end{array}$ & $\begin{array}{l}5 / 6 \text { survivors after VAS had RI } \\
2 / 3 \text { survivors without VAS } \\
\text { had RI }\end{array}$ \\
\hline Freedman 1999 [13] & Retrospective & $\begin{array}{l}34 \text { patients had VAS } \\
17 \text { survived }>2 \text { years } 14 \\
\text { studied ( } 4 \text { had PUV) }\end{array}$ & 2-year OS: $50 \%$ & $\begin{array}{l}36 \%(5 / 14) \text { had kidney trans- } \\
\text { plant } \\
21 \%(3 / 14) \text { had RI } \\
\text { Of } 4 \text { PUV patients: } \\
\text { one had normal RF, } 2 \text { had RI } \\
\text { and one had ESRD } \\
3 \text { required bladder augmenta- } \\
\text { tion }\end{array}$ \\
\hline Morris 2013 [6] & Randomized controlled trial & $\begin{array}{l}31 \text { fetuses (16 VAS, } 15 \text { no } \\
\text { treatment) }\end{array}$ & $\begin{array}{l}\text { VAS: } 8 / 16(50 \%) \text { survived the } \\
\text { neonatal period } \\
\text { No treatment: } 4 / 15(27 \%) \\
\text { survived the neonatal period }\end{array}$ & $\begin{array}{l}\text { VAS: } 2 / 16 \text { patients had normal } \\
\text { RF at } 2 \text { years } \\
\text { No treatment: none had nor- } \\
\text { mal RF at } 2 \text { years }\end{array}$ \\
\hline Holmes 2001 [11] & Retrospective & $\begin{array}{l}14 \text { fetuses with PUV ( } 9 \text { VAS, } 2 \\
\text { FVA, } 2 \text { bladder marsupializa- } \\
\text { tion, } 1 \text { cutaneous ureteros- } \\
\text { tomy) }\end{array}$ & $\begin{array}{l}\text { 8/14 (57\%) survived } \\
\text { (12 months-19 years) }\end{array}$ & $\begin{array}{l}5 / 8(63 \%) \text { survivors had RI, } 2 \text { of } \\
\text { them had kidney transplant }\end{array}$ \\
\hline Quintero 1995 [25] & Cohort & $\begin{array}{l}13 \text { fetuses ( } 4 \text { standard VAS, } \\
2 \text { urethral stents, } 1 \text { PUV per- } \\
\text { meation, } 4 \text { diagnostic fetal } \\
\text { cystoscopy only) }\end{array}$ & $\begin{array}{l}\text { Standard VAS: } 3 / 4 \text { survived } \\
\text { Urethral stents: } 2 / 2 \text { survived } \\
\text { One patient had PUV per- } \\
\text { meation was terminated }\end{array}$ & $\begin{array}{l}\text { VAS: } \\
1 / 3 \text { survivors had normal RF } \\
2 \text { had ESRD } \\
\text { Urethral stents: no data on RF }\end{array}$ \\
\hline Welsh 2003 [26] & Cohort, retrospective & $\begin{array}{l}10 \text { fetuses had intervention: } \\
1 \mathrm{HA} \\
2 \mathrm{HA}+\text { guidewire passage } \\
4 \text { guidewire only } \\
1 \mathrm{HA}+\text { guidewire pas- } \\
\text { sage + VAS } \\
\text { 2. guidewire + VAS } \\
\text { 3. Only diagnostic cystoscopy }\end{array}$ & $\begin{array}{l}\text { OS: } 50 \%(5 / 10) \text { in those } \\
\text { who had intervention } \\
\text { (16-34 months) }\end{array}$ & $\begin{array}{l}\text { Overall, } 3 / 5 \text { survivors had } \\
\text { normal RF } \\
\text { 2/3 PUV survivors had normal } \\
\text { RF }\end{array}$ \\
\hline Ruano 2015 [23] & $\begin{array}{l}\text { Case-control, prospectively } \\
\text { collected data }\end{array}$ & $\begin{array}{l}111 \text { fetuses (34 FVA, 16 VAS, } \\
61 \text { no intervention) }\end{array}$ & $\begin{array}{l}\text { Intervention group: 40\% } \\
\text { 6-month OS } \\
\text { FVA: 38\% 6-month OS } \\
\text { VAS: 44\% 6-month OS } \\
\text { No intervention: 6-month } \\
20 \% \text { OS }\end{array}$ & $\begin{array}{l}\text { FVA: better RF than no inter- } \\
\text { vention ( } 75 \% \text { had normal RF } \\
\text { vs. } 39 \% \text { ) } \\
\text { VAS: similar RF to no interven- } \\
\text { tion group ( } 60 \% \text { had normal RF } \\
\text { vs. } 39 \% \text { ) }\end{array}$ \\
\hline
\end{tabular}

FVA: fetoscopic valve ablation, ESRD: end-stage renal disease, HA: hydroablation, OS: overall survival, PUV: posterior urethral valve, RF: renal function, RI: renal impairment, VAS: vesicoamniotic shunt

Abdelhalim et al. demonstrated improved hydronephrosis in $61.9 \%$ of renal units in patients treated with oxybutynin relative to $34.8 \%$ in those actively observed. Further, vesicoureteral reflux (VUR) resolved in $62.5 \%$ of renal units in the oxybutynin arm versus $25 \%$ in the observation arm. However, the reported hydronephrosis and
VUR resolution did not translate into a significant difference in renal function outcome, UTI recurrence rates or attainment of toilet training. The authors suggest that anticholinergic treatment can be considered in infants and young children with persistent hydronephrosis after endoscopic valve ablation [30]. 
Parents and caregivers should be informed that anticholinergics are associated with common, but tolerable, dose-related adverse events including dry mouth, facial flushing and constipation. Although some studies reported a negative effect on memory and cognition in adults treated with anticholinergics, there is no evidence to support such an effect in children [33,32]. 32 agonists, such as mirabegron, have been used successfully to treat overactive bladder and DO in adults with less adverse effects compared to anticholinergics. To the best of our knowledge, there have been no studies evaluating the use $\beta 2$ agonists for treatment of bladder dysfunction secondary to PUV to date. If proven effective, $\beta 2$ agonists will hopefully overcome some of the limitations of anticholinergic therapy.

While some investigators linked anticholinergic treatment to drug-induced myogenic failure [34], others believe that myogenic failure is the result of untreated BD in childhood [35]. In some studies, myogenic failure was observed only in patients treated with anticholinergics. Therefore, it was assumed that myogenic failure is the result of anticholinergic treatment [31,34,36]. For instance, Misseri et al. observed myogenic failure in 5.9\% of patients, all had hypocompliant bladders at baseline and were treated with anticholinergics. Myogenic failure developed only after institution of anticholinergic treatment and resolved once anticholinergic treatment was discontinued. Other investigators presumed that untreated bladder dysfunction would result in bladder decompensation and eventually myogenic failure [35,37]. Androulakakis et al. diagnosed myogenic failure in 10 of 18 (55.5\%) adolescent and pubertal boys treated for PUV during infancy. None of those patients received anticholinergic therapy. The authors of that study assumed that secondary bladder neck obstruction resulted in myogenic failure since 5 of those patients had improved uroflow pattern following alpha-blocker treatment or bladder neck incision (BNI) [38].

\section{- Alpha-blocker treatment:}

Secondary bladder neck obstruction (BNO) is thought to contribute to $\mathrm{BD}$ and continued renal deterioration in PUV patients. The diagnosis of BNO in patients with PUV is challenging since most patients have bladder neck hypertrophy on VCUG and a prominent posterior lip of the bladder neck on cystoscopy. The diagnosis requires the combination of a high detrusor voiding pressure and a low urinary flow rate in the absence of distal obstruction by residual valves or urethral stricture. Alpha-blocker treatment and BNI have been used arbitrarily in the literature to treat secondary BNO in patients with history of PUV. To the best of our knowledge, the efficacy or safety of both treatment modalities for treating bladder neck obstruction has not been examined in a comparative design. Compared to alpha-blocker treatment, the effects of BNI including the potential risk of retrograde ejaculation are obviously long-lasting and probably irreversible. In a heterogeneous group of patients with persistent upper tract dilation and history of PUV ablation, Donohoe et al. identified that 7 patients with BNO: 5 were treated with alpha blocker and two with BNI. Five subsequently had resolved or improved hydronephrosis [36]. Similarly, Combs et al. diagnosed unequivocal secondary BNO in $22 \%$ of their cohort of PUV patients. They demonstrated $60 \%$ reduction of the mean voiding pressure and doubling of Qmax and Qave with alpha-blocker treatment [39]. Abraham and colleagues treated 42 patients with elevated postvoid residual (PVR) following PUV ablation with powdered terazosin tablets (0.02 to $0.4 \mathrm{mg} / \mathrm{kg} \mathrm{OD})$. After an average followup of 17 months, there was an $85 \%$ reduction of PVR with improved urinary stream and improved upper tract dilation [40]. The ideal duration of alpha-blocker therapy remains unclear.

\section{- Continuous antibiotic prophylaxis (CAP):}

As long as the controversy of using CAP in primary VUR and antenatal hydronephrosis is not solved, the use of CAP in more complex clinical situations as in PUV will be even more perplexing. To our knowledge, there are no well-designed studies examining the utility of CAP in reducing UTI risk in PUV patients. Therefore, it seems prudent to consider CAP in newborns before valve ablation, patients with persistent VUR after PUV ablation and those with recurrent UTIs.

\section{- Desmopressin for nephrogenic diabetes insipidus:}

As many as $78 \%$ of PUV patients have polyuria due to irreversible renal tubular damage resulting in loss of the renal concentrating capacity [41]. Polyuria is thought to contribute to $\mathrm{BD}$, urinary incontinence and persistent upper tract dilation [41-43]. Naghizadeh et al. treated 16 PUV patients with polyuria and hypo-osmolar urine with desmopressin ( $0.4 \mathrm{mg} /$ day in two divided doses) for 3 months. The mean patient age in that study was 6.8 years (range 2 to 11 years). Desmopressin treatment resulted in a significant reduction of 24-hour urine volumes and an increase in the urine osmolarity. The response to desmopressin was more pronounced in patients with $\mathrm{BD}$, normal baseline serum $\mathrm{ADH}$ levels and higher baseline creatinine clearance. However, the improved urine characteristics after desmopressin 
treatment did not result in improved voiding symptoms in those who were toilet trained [43].

\section{- Angiotensin-converting enzyme inhibitors (ACE- Is):}

Alterations of the renin-angiotensin system play a crucial role in regulating glomerular hemodynamics and were claimed as one of the contributing factors to progression of renal damage in PUV patients. A study by Bajpai et al. demonstrated decline of serum creatinine and downregulation of the plasma renin activity following PUV ablation. Longer follow-up demonstrated a $13-71 \%$ decline of GFR with a $4-23.5 \%$ rise of plasma renin activity. Treatment with ACE-Is (Enalapril $0.14 \mathrm{mg} / \mathrm{kg} /$ day) for a mean of $18.2 \pm 4$ months resulted in a $55-64.6 \%$ decrease in micro-albuminuria, a modest rise (4.2-5.9\%) of GFR and a marginal decrease in serum creatinine [44]. It was also hypothesized that ACE-I treatment does not only ameliorate proteinuria and slow the progression of chronic kidney disease (CKD), but it also inhibits some of the pathologic bladder changes induced by bladder outlet obstruction. In a neonatal rabbit model, captopril was found to inhibit serosal hyperplasia and collagen deposition induced by partial bladder outlet obstruction, but had minimal effect in a rat model of bladder outlet obstruction [45]. This hypothetical benefit of ACE-Is on bladder remodeling was not, however, tested in humans.

\section{- Nocturnal bladder emptying:}

Diminished bladder sensations, polyuria and incomplete bladder emptying exacerbate BD in PUV patients. A strict regimen of timed daytime voiding, double voiding, anticholinergics and intermittent daytime catheterization sometimes fails to improve upper tract dilation. Nocturnal bladder drainage in patients with poor bladder compliance is thought to decrease UTI risk, upper tract dilation and post-obstructive diuresis. It could also improve continence and reduce progression to renal failure. It has been assumed that bladder drainage overnight would lower the bladder pressure, provide a period of bladder rest and subsequently improve bladder dynamics and upper tract outcomes $[42,46]$. After initiating a program of nocturnal bladder emptying with an indwelling overnight catheter, intermittent nighttime catheterization or frequent nocturnal double voiding in 12 boys with valve bladder syndrome, Koff et al. reported improved hydronephrosis and renal function. The outcome of patients treated with overnight catheter drainage was comparable to those treated with bladder augmentation $[42,46]$.

\section{- Biofeedback and pelvic floor exercise:}

Pelvic floor dysfunction is thought to contribute to bladder dysfunction in PUV patients. Children with DO may tighten their pelvic floor and external sphincter to maintain continence. Non-relaxing pelvic floor together with DO could raise the bladder pressure and lead to worsening hydronephrosis. Non-relaxing pelvic floor may also lead to poor bladder emptying, high PVR and eventually bladder decompensation and myogenic failure. Using biofeedback is thought to improve bladder emptying, lower the detrusor pressure and eventually improve hydronephrosis and functional bladder capacity. Ansari et al. used biofeedback and pelvic floor exercise to treat PUV patients with persistent lower urinary tract dysfunction. Of 30 patients included in that study, $70 \%$ had symptomatic improvement. Mean cystometric bladder capacity increased from $65 \%$ to $87.25 \%$ of the expected capacity after treatment and hydronephrosis improved in $21 \%$. Patients with DO, larger bladder capacity and lower end-filling pressure were more likely to benefit from treatment [47].

\section{Surgical aspects of PUV:}

\section{- Valve ablation methods:}

If the diagnosis of PUV is suspected, bladder drainage is recommended, preferably with a non-ballooned catheter. Once the patient is stabilized, infravesical obstruction should be removed by endoscopic valve ablation. A variety of techniques have been described for PUV ablation including: cold knife ablation (Fig. 4b, c and d), Fogarty balloon, hook diathermy electrode (Fig. 4e and 4f) hot loop resectoscope (Fig. 4g) and valve ablation using bugbee electrode (Fig. 4h). Compared to cold knife ablation, valve resection using electrical current has been associated with a relatively higher incidence of complications including postoperative retention and urethral stricture $[48,49]$. Recently, there has been a growing interest in the use of holmium or thallium laser to ablate valves with comparable outcomes. Laser ablation provides the potential benefit of controlled ablation of valves with a lower risk of urethral stricture due to limited tissue penetration, short catheterization time and less irritative symptoms and risk of retention when compared to thermal ablation [50-52]. These methods proposed for ablation of valves have not been compared in a randomized fashion and the choice of valve ablation method remains subject to surgeon preference and institutional protocols. Postnatal management of PUV is summarized in Fig. 5. 


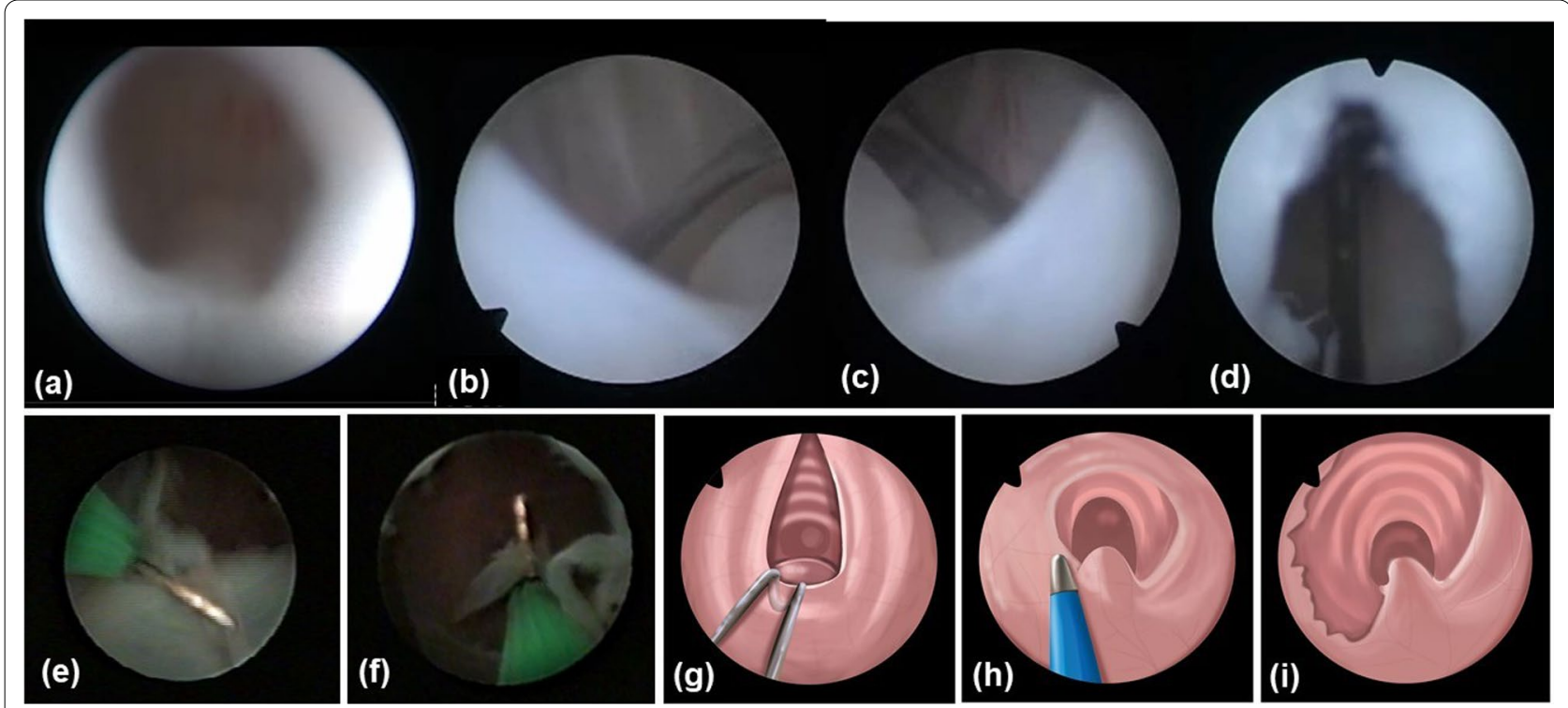

Fig. 4 Endoscopic appearance of type I PUV (a). Valve ablation using cold knife at 5 (b), 7 (c) and 12 o'clock (d). Hook diathermy electrode ablation of PUV at 5 (e) and 12 o'clock (f). Valve ablation using hot loop resectoscope $(\mathbf{g})$ and bugbee electrode (h). After valve ablation at 12 and 5 o'clock

\section{- Urinary diversion in patients with PUV:}

\section{- Effect of urinary diversion on bladder dynamics:}

With miniaturization of pediatric endoscopy, PUV ablation is currently considered the standard treatment of PUV. Vesicostomy is typically reserved for severe lowbirth weight newborns whose urethra cannot accommodate the scope for valve ablation or in those with high PVR, persistently elevated serum creatinine or recurrent UTIs despite adequate valve ablation [53]. Advocates of urinary diversion believe that diversion provides lowpressure drainage of the urinary tract, resulting in at least temporary and rapid improvement of renal function $[54,55]$. Some authors believe that prolonged urinary diversion may lead to bladder defunctionalization with subsequent loss of bladder compliance and increased the need for bladder augmentation. This belief is supported by the higher prevalence of reduced bladder capacity, elevated end-filling pressure, impaired compliance and more DO reported in some children treated initially with diversion followed by undiversion and valve ablation at an older age, relative to those treated with primary valve ablation [56,57]. On the contrary, other studies reported increased bladder capacity and improved bladder dynamics after a period of temporary diversion $[58,59]$. Advocates of diversion believe that putting the bladder temporarily at rest may reverse some of the pathologic bladder changes resulting from bladder outlet obstruction. They debate reports of poor urodynamic outcomes following diversion by the opinion that diversion was initially chosen as a line of treatment for high-risk patients who sustained significant bladder damage in utero as a result of bladder outlet obstruction [60]. The future need for complex reconstructive procedures with repeated anesthetic exposure to restore the urinary tract anatomy is another clear limitation of diversion.

\section{- Vesicostomy versus supravesical diversion}

Before the concept of valve bladder syndrome became widely accepted, supravesical diversion, with ureterostomy or pyelostomy, was proposed to treat what was thought to be concomitant anatomic obstruction at the ureterovesical junctions. Although supravesical diversion provides timely decompression of the dilated upper tracts, it may have more deleterious effects on bladder dynamics relative to vesicostomy by preventing bladder cycling. Duckett further assumed that the valve bladder is the result of supravesical diversion [61]. This assumption is readily rebutted by the presence of similar urodynamic abnormalities in children treated with primary valve ablation and has never been diverted. If one has to choose, vesicostomy is preferable to supravesical diversion in terms of preserving bladder function. In a study by Jayanthi et al. including 31 PUV patients treated with urinary diversion, bladder augmentation was required in only one of 21 patients treated with vesicostomy compared to 7 of 10 patients treated with supravesical diversion. The majority of patients treated with vesicostomy 


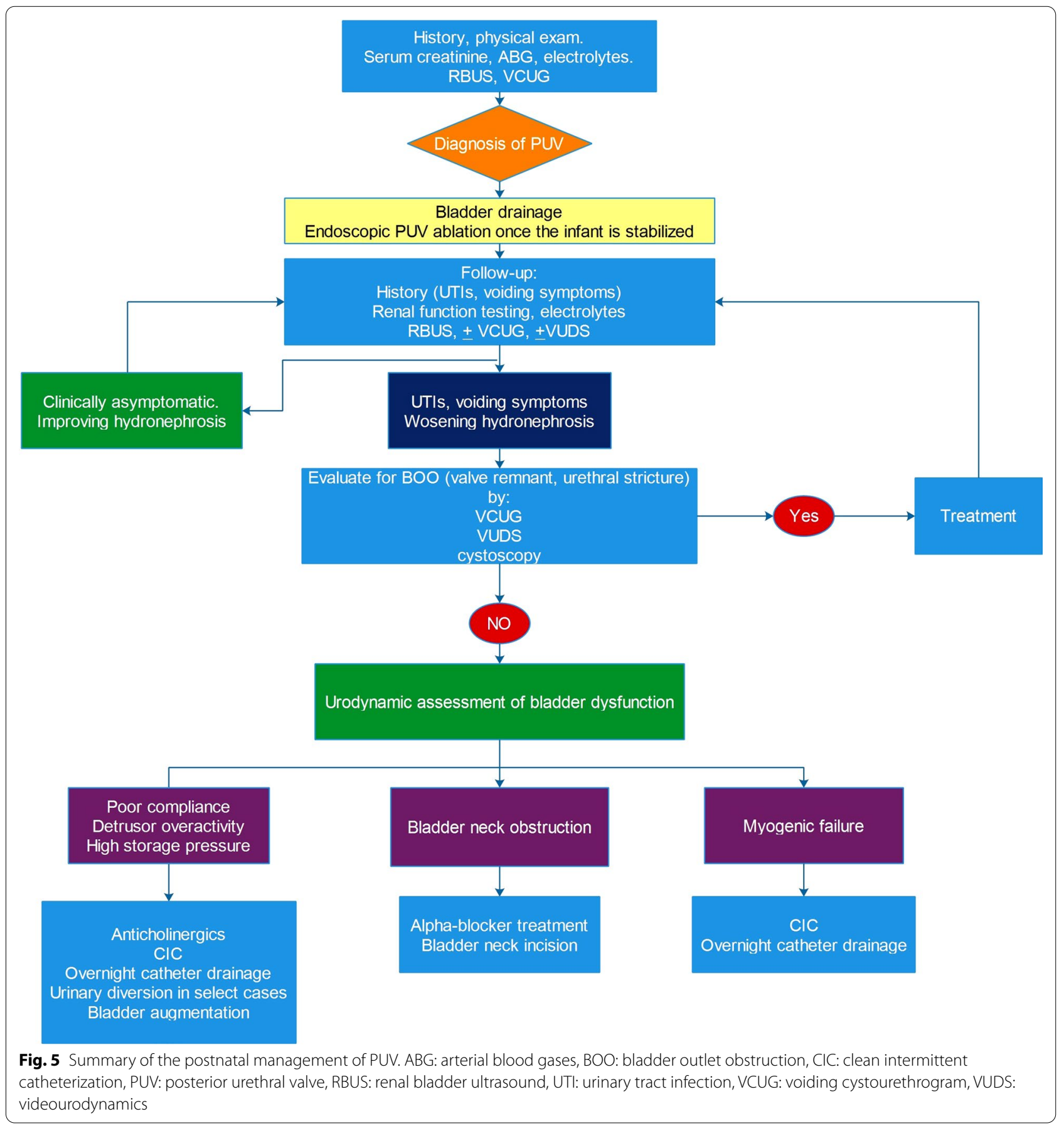

had normal bladder capacities with storage pressures less than $30 \mathrm{cmH}_{2} \mathrm{O}$ after vesicostomy reversal. Notably, the decision for bladder augmentation in that study was solely based on the presence of bladder trabeculation and a small bladder capacity on cystogram without formal urodynamic testing [62]. Conversely, Ghanem et al. demonstrated preservation of the bladder capacity and compliance in the majority of patients treated with bilateral Sober ureterostomy for a mean of 55 months. However, $42 \%$ of this study cohort had impaired renal function at last follow-up [55]. 
- Effect of urinary diversion on renal function, progression to ESRD and renal transplantation outcome:

In addition to the possible adverse effect of urinary diversion on bladder dynamics, its long-term benefit to renal function remains debatable $[63,64]$. In a study comparing the progression to ESRD among patients with stage III CKD secondary to PUV, patients treated with valve ablation only had a higher incidence of ESRD at 1-year follow-up than those treated with valve ablation followed by vesicostomy or supravesical diversion. However, the cumulative incidence of ESRD was not significantly different among these three treatment groups with longer follow-up. This study provides insights that diversion may not prevent or decrease the ultimate risk of ESRD, but it could possibly delay the progression to ESRD and the need for renal replacement therapy in a select patient population [55,64]. Delaying the onset of ESRD should not be underestimated since dialysis management in infants and small children is challenging and carries a high mortality risk [65]. Also, renal transplantation (RT) is technically easier and has more favorable outcomes in older patients [66].

A study by Bartsch et al. found less favorable transplantation outcomes in PUV children treated with extensive urinary tract reconstruction than those treated with primary valve ablation or vesicostomy and delayed valve ablation. Accordingly, the authors recommended avoiding extensive urinary tract reconstruction in patients approaching ESRD [67]. However, it is also possible that those who had more significant BD required urinary tract reconstruction to prevent or at least delay the onset of ESRD.

These conflicting data about the value of diversion, like many other debates in the field of PUV, highlight the obvious limitations of PUV literature including insufficiently powered studies comparing heterogeneous patient populations with variable baseline characteristics, outcome definition and follow-up protocols. Additionally, the choice of primary treatment as well as subsequent management is clearly subject to selection bias. In summary, every PUV patient should be evaluated thoroughly and on individual basis in order to select patients who could potentially benefit from urinary diversion and also to optimize the timing, duration and choice of the diversion technique.

\section{- Bladder neck incision (BNI):}

Bladder neck hypertrophy is one of the factors thought to contribute to bladder dysfunction in PUV patients [38].
The true existence of secondary bladder neck obstruction and its effect on long-term outcome of PUV patients have been debated [60]. BNI or alpha-blocker treatment was proposed to treat bladder neck hypertrophy, improve bladder dynamics and prevent renal deterioration in a handful of studies with conflicting results $[34,38,68,69]$. In a prospective study, Kajbafzadeh et al. reported improved urodynamic parameters, higher VUR resolution rates, lower risk of myogenic failure and less need for anticholinergic treatment when BNI was performed concomitantly with PUV incision, compared to those who had PUV ablation only [68]. Conversely, Singh et al. reported improved peak flow rate and PVR, but similar compliance, DO, end-filling pressure, maximum Pdet at Qmax and reflux resolution rate in a prospective randomized study comparing PUV ablation alone to concomitant PUV and BNI [69].

The long-term sequelae of BNI on urinary continence and ejaculation have been questioned [70]. Taskinen et al. reported ejaculation failure in two of 19 adult patients treated with PUV ablation and BNI during childhood. Interestingly, dry ejaculate was also reported in one of 15 patients treated with PUV ablation only [71]. Keihani reported no effect of BNI on continence, ejaculation or semen quality in 18 adult patients who had concomitant PUV ablation and BNI as children [72]. Similar results were echoed by Hennus in 40 adult participants who had superficial BNI at a median age of 4.7 years [73].

\section{- Botulinum toxin injection:}

Mokhless et al. examined the effect of botulinum toxin injection into the bladder neck to address the potential bladder neck dysfunction in PUV patients. With 10 patients in both the study and control groups, they failed to demonstrate any significant effects of bladder neck botulinum toxin injection on urodynamic variables, hydronephrosis or VUR resolution rates 6 months after the procedure [70]. This study was, however, criticized by relying on visual inspection for diagnosing bladder neck obstruction and using a small dose of botulinum toxin to inject the bladder neck. Such a small dose may not be enough to block alpha receptors in the bladder neck. Also, follow-up UDS were performed 6 months after botulinum toxin, a time at which the effect of botulinum toxin has probably waned. Since almost all patients with PUV have bladder neck hypertrophy on VCUG, identifying patients with definite bladder neck obstruction who could benefit from bladder neck intervention is challenging and requires the combination of videourodynamics with elevated voiding pressure, uroflowmetry with obstructed flow and a quiet electromyography. 


\section{- Bladder reconstruction in PUV patients:}

AC may be required in some PUV patients in whom less invasive therapeutic interventions have failed to correct $\mathrm{BD}$, preserve the upper tract or achieve continence. Catheterizable channels can be concomitantly performed to facilitate $\mathrm{CIC}$ in patients with sensate urethras. Owing to the well-known, long-term and serious consequences of $\mathrm{AC}$, including metabolic complications, mucus production, stone formation and risk of malignancy, careful patient evaluation and family counseling are mandatory before endorsing the decision of AC. These complications are more likely to arise in the pediatric population that are expected to survive for several decades. Some of these complications could be life threatening, particularly with immunosuppression following RT [74,75]. Alfrey reported AC takedown following RT due to serious UTIs that were life threatening in two patients and resulted in graft loss in another patient [74].

Importantly, most adolescents with PUV demonstrate increased bladder capacity and improved compliance [1], thus reducing the need for $\mathrm{AC}$ as patients age. Unlike children with bladder exstrophy or neurogenic bladder, approximately half of PUV patients receiving bladder augmentation can void spontaneously without significant residual urine [76,77].

While augmentation enterocystoplasty is considered the standard approach, ureterocystoplasty is an attractive option in PUV patients with massively dilated ureters. It can avoid some of the complications of enterocystoplasty while achieving durable and comparable outcomes in properly selected patients [78]. Although AC can help achieve continence and stabilize or improve hydronephrosis, there is evidence that AC may not alter the natural history of CKD in PUV patients with renal dysplasia. Bhatti et al. found that $\mathrm{AC}$ has failed to slow the progression of CKD in PUV patients who had pre-AC serum creatinine levels higher than $2 \mathrm{mg} / \mathrm{dl}$ and nadir creatinine levels higher than $1 \mathrm{mg} / \mathrm{dl}[79]$.

- Renal transplantation in patients with PUV:

- Outcomes of RT in PUV patients:

PUV, among other causes of obstructive uropathy, remains a frequent indication for pediatric renal transplantation [80,81]. Detailed pre-transplant evaluation, including endoscopic examination and videourodynamics, as well as proper pre- and post-transplant management of the underlying $\mathrm{BD}$ is crucial to improve transplantation outcomes and minimize urological complications.

Results of kidney transplantation in children with PUV are mixed, but most recent studies demonstrate graft survival rates and renal function outcomes similar to children with other causes of ESRD [81-85]. Hebenstreit et al. reported similar graft survival in patients with PUV compared to patients with non-urologic causes of ESRD [85]. Fewer studies have shown less favorable transplantation outcomes in PUV patients. For instance, Churchill et al. and others $[86,87]$ reported lower graft survival (40-50\% graft survival at 5 years) than in children with other urologic anomalies or medical causes of ESRD [88]. Notably, graft losses in some of these studies were attributed to causes unrelated to BD (e.g., vascular complication, acute or chronic graft rejection). Compared to patients with other urinary tract anomalies, Salomon et al. observed similar 5- and 10-year graft survival in PUV patients. Nonetheless, patients with PUV had significantly higher serum creatinine at 10 years relative to controls. Although not statistically significant, urological complications, especially ureteral obstruction, were more common in PUV [89]. Likewise, Bartsch reported lower 5-year creatinine clearance in PUV patients receiving kidney transplantation relative to controls with nonobstructive causes of ESRD, despite similar patient and graft survival rates [67]. The improved graft survival and older age at transplantation shown in subsequent studies $[75,82,83,90]$ probably reflects improved understanding and better management of the underlying BD.

- Primary mode of treatment and outcomes of RT:

Fine et al. reported similar transplantation outcomes in patients initially treated with valve ablation, vesicostomy or supravesical diversion [84]. Conversely, Bartsch et al. observed a lower 5-year creatinine clearance and higher prevalence of incontinence in patients treated primarily with supravesical diversion and extensive urinary tract reconstruction [67]. These unfavorable outcomes reflect a higher prevalence of $\mathrm{BD}$ in patients treated with urinary diversion. Although undiversion is preferable before RT, successful transplantation has been reported into incontinent diversions including vesicostomy [91-93].

- Timing of augmentation cystoplasty: before or after RT:

BD should be carefully evaluated and adequately addressed before and sometimes after RT to optimize RT outcomes. AC may be required before RT for patients with poor compliance or DO refractory to less invasive treatment measures. Interestingly, graft deterioration and progressive hydronephrosis have been reported following RT in patients with urodynamically adequate bladders on pre-transplant evaluation, necessitating post-RT $\mathrm{AC}$. These findings highlight the dynamic nature of $\mathrm{BD}$ in 
children with PUV and the need for continuous monitoring of bladder function even after RT $[94,95]$. Compared to post-RT AC, pre-RT AC poses a lower risk of postoperative infectious complications in immunosuppressed patients and avoids injuring the graft pedicle [96]. On the other hand, pre-transplantation AC has several potential hazards. First, AC is a major surgery with considerable morbidity in patients with ESRD. It may also preclude peritoneal dialysis. Additionally, the augment and its pedicle are at risk of injury during RT. Further, pre-RT AC may pose a higher risk of symptomatic UTIs, particularly with oligoanuric patients. Management of the metabolic consequences of $\mathrm{AC}$, particularly metabolic acidosis, is another challenge in patients not yet on dialysis. Finally, BD may improve with polyuria control after RT negating the need for AC.

To the best of our knowledge, pre-RT and post-RT were not compared in a prospective fashion. Taghizadeh et al. compared pre- and post-RT AC in a mixed cohort of children with $\mathrm{BD}$. Ureteric complications were more common in the group that had RT first. Graft failure occurred in $1 / 10$ patients who had AC first due to renal artery thrombosis compared to $4 / 8$ who had RT first. In the group who had RT first, graft failures were due to (ureterostomy stenosis in one, recurring UTIs in two and chronic graft rejection in the fourth patient). There was no difference in hospital stay or the incidence of UTIs in the early postoperative period between both groups. The authors concluded that performing AC before RT is a safer approach to protect the renal allograft and its ureter and prevent such a major procedure in an immunocompromised child [96]. On the other hand, successful transplantation into even a vesicostomy, or other forms of incontinent urinary diversion, has been reported. This approach allows deferring AC until the child is old enough for cystoplasty and CIC can be appropriately performed [91,92].

\section{Conclusions}

Despite the substantial technical refinements accomplished, antenatal intervention for fetuses with a presumptive diagnosis of PUV remains associated with significant fetal and maternal morbidity. Besides, there is no consensus on the ideal patient selection criteria. Antenatal intervention with VAS or FVA improves perinatal survival compared to observation in select population. However, the benefit to long-term renal and bladder function is not clear with some data in favor of FVA. There is a growing evidence that anticholinergic treatment improves upper tract and continence outcome in infants and young children. A paucity of studies suggests a potential role for alpha-blocker treatment, nocturnal bladder drainage and biofeedback in select PUV patients. Urinary diversion should not be the standard approach. It may delay, but does not prevent, progression to ESRD in properly selected patients. Successful RT outcomes could be achieved in children with PUV progressing to ESRD, but management of the underlying BD is key. The lack of well-designed and adequately powered prospective studies, rarity of disease, variability of presentation, heterogeneity of patient population, relatively short follow-up and non-uniform outcome measures are obvious and almost inevitable limitations to PUV literature.

\section{Abbreviations}

ACE-Is: Angiotensin-converting enzyme inhibitors; AC: Augmentation cystoplasty; ADC: Apparent diffusion coefficient; BD: Bladder dysfunction; BNI: Bladder neck incision; BNO: Bladder neck obstruction; CAP: Continuous antibiotic prophylaxis; CKD: Chronic kidney disease; DO: Detrusor overactivity; ESRD: End-stage renal disease; FVA: Fetoscopic valve ablation; LUTO: Lower urinary tract obstruction; PUV: Posterior urethral valve; PVR: Postvoid residual; RT: Renal transplantation; UTI: Urinary tract infection; VAS: Vesicoamniotic shunt; VUR: Vesicoureteral reflux.

\section{Acknowledgements}

We would like to acknowledge Dr. Heidi Stephany and Dr. Azam Eghbal from the Children's Hospital of Orange County, CA, USA, for providing the prenatal ultrasound and fetal MRI images, Dr. Sherif Soliman from Ain Shams University, Cairo, Egypt, for providing endoscopic images of valve ablation using hook diathermy electrode and Dr. Heba Mahdi from Mansoura University, for providing illustrations of valve ablation using the resectoscope and bugbee electrode.

\section{Authors' contributions}

AA was involved in conceptualization, data acquisition, methodology, writing the original draft. ATH helped in conceptualization, methodology, supervision, final manuscript reviewing and editing. All authors have read and approved the manuscript.

\section{Funding}

None.

\section{Availability of data and materials}

Data sharing is not applicable to this article as no datasets were generated or analyzed during the current study.

\section{Declarations}

Ethics approval and consent to participate

Not applicable.

Consent for publication

Not applicable.

Competing interests

The authors declare that they have no competing interests.

Received: 19 May 2021 Accepted: 5 September 2021

Published online: 30 September 2021

\section{References}

1. Peters CA, Bolkier M, Bauer SB, Hendren WH, Colodny AH, Mandell J et al (1990) The urodynamic consequences of posterior urethral valves. J Urol 144(1):122-126 
2. Freedman AL, Johnson MP, Gonzalez R. Fetal therapy for obstructive uropathy: past, present, future? Pediatr Nephrol. 2000;14(2):167-76. doi: https://doi.org/10.1007/s004670050035.

3. Sarhan OM, Helmy TE, Alotay AA, Alghanbar MS, Nakshabandi ZM, Hafez AT (2013) Did antenatal diagnosis protect against chronic kidney disease in patients with posterior urethral valves? A multicenter study Urology 82(6):1405-1409. https://doi.org/10.1016/j.urology.2013.07.058

4. Bernardes LS, Aksnes G, Saada J, Masse V, Elie C, Dumez Y et al (2009) Keyhole sign: how specific is it for the diagnosis of posterior urethral valves? Ultrasound in obstetrics \& gynecology : the official journal of the International Society of Ultrasound in Obstetrics and Gynecology 34(4):419-423. https://doi.org/10.1002/uog.6413

5. Robyr R, Benachi A, Daikha-Dahmane F, Martinovich J, Dumez Y, Ville Y (2005) Correlation between ultrasound and anatomical findings in fetuses with lower urinary tract obstruction in the first half of pregnancy. Ultrasound in obstetrics \& gynecology : the official journal of the International Society of Ultrasound in Obstetrics and Gynecology 25(5):478-482. https://doi.org/10.1002/uog.1878

6. Morris RK, Malin GL, Quinlan-Jones E, Middleton LJ, Hemming K, Burke D et al (2013) Percutaneous vesicoamniotic shunting versus conservative management for fetal lower urinary tract obstruction (PLUTO): a randomised trial. Lancet 382(9903):1496-1506. https://doi.org/10.1016/ S0140-6736(13)60992-7

7. Pico H, Dabadie A, Bourliere-Najean B, Philip N, Capelle M, Aschero A et al (2014) Contribution of the foetal uro-MRI in the prenatal diagnosis of uronephropathies. Diagn Interv Imaging 95(6):573-578. https://doi.org/ 10.1016/j.diii.2014.02.011

8. Faure A, Panait N, Panuel M, Alessandrini P, D'Ercole C, Chaumoitre Ket al (2017) Predicting postnatal renal function of prenatally detected posterior urethral valves using fetal diffusion-weighted magnetic resonance imaging with apparent diffusion coefficient determination. Prenat Diagn 37(7):666-672. https://doi.org/10.1002/pd.5063

9. Crombleholme TM, Harrison MR, Golbus MS, Longaker MT, Langer JC, Callen PW et al (1990) Fetal intervention in obstructive uropathy: prognostic indicators and efficacy of intervention. Am J Obstet Gynecol 162(5):1239_ 1244. https://doi.org/10.1016/0002-9378(90)90026-4

10. Lipitz S, Ryan G, Samuell C, Haeusler MC, Robson SC, Dhillon HK et al (1993) Fetal urine analysis for the assessment of renal function in obstructive uropathy. Am J Obstet Gynecol 168(1 Pt 1):174-179. https://doi.org/ 10.1016/s0002-9378(12)90909-6

11. Holmes N, Harrison MR, Baskin LS (2001) Fetal surgery for posterior urethral valves: long-term postnatal outcomes. Pediatrics 108(1):E7. https:// doi.org/10.1542/peds.108.1.e7

12. Nicolini U, Tannirandorn Y, Vaughan J, Fisk NM, Nicolaidis P, Rodeck CH (1991) Further predictors of renal dysplasia in fetal obstructive uropathy: bladder pressure and biochemistry of "fresh" urine. Prenat Diagn 11(3):159-166. https://doi.org/10.1002/pd.1970110305

13. Freedman AL, Johnson MP, Smith CA, Gonzalez R, Evans MI (1999) Longterm outcome in children after antenatal intervention for obstructive uropathies. Lancet 354(9176):374-377. https://doi.org/10.1016/S01406736(98)11006-1

14. Dommergues M, Muller F, Ngo S, Hohlfeld P, Oury JF, Bidat L et al (2000) Fetal serum beta2-microglobulin predicts postnatal renal function in bilateral uropathies. Kidney Int 58(1):312-316. https://doi.org/10.1046/j. 1523-1755.2000.00167.x

15. Craparo FJ, Rustico M, Tassis B, Coviello D, Nicolini U (2007) Fetal serum beta2-microglobulin before and after bladder shunting: a 2-step approach to evaluate fetuses with lower urinary tract obstruction. J Urol 178(6):2576-2579. https://doi.org/10.1016/j.juro.2007.08.052

16. Morris RK, Quinlan-Jones E, Kilby MD, Khan KS (2007) Systematic review of accuracy of fetal urine analysis to predict poor postnatal renal function in cases of congenital urinary tract obstruction. Prenat Diagn 27(10):900911. https://doi.org/10.1002/pd.1810

17. Buffin-Meyer B, Klein J, Breuil B, Muller F, Moulos P, Groussolles M et al (2018) Combination of the fetal urinary metabolome and peptidome for the prediction of postnatal renal outcome in fetuses with PUV. J Proteomics 184:1-9. https://doi.org/10.1016/j.jprot.2018.06.012

18. Morris RK, Malin GL, Khan KS, Kilby MD (2009) Antenatal ultrasound to predict postnatal renal function in congenital lower urinary tract obstruction: systematic review of test accuracy. BJOG : an international journal of obstetrics and gynaecology 116(10):1290-1299. https://doi.org/10.1111/j. 1471-0528.2009.02194.x

19. Jeong BD, Won HS, Lee MY (2018) Perinatal Outcomes of Fetal Lower Urinary Tract Obstruction After Vesicoamniotic Shunting Using a DoubleBasket Catheter. J Ultrasound Med 37(9):2147-2156. https://doi.org/10. 1002/jum.14565

20. Nassr AA, Shazly SAM, Abdelmagied AM, Araujo Junior E, Tonni G, Kilby MD et al (2017) Effectiveness of vesicoamniotic shunt in fetuses with congenital lower urinary tract obstruction: an updated systematic review and meta-analysis. Ultrasound Obstet Gynecol 49(6):696-703. https://doi.org/10.1002/uog.15988

21. Ruano R, Sananes N, Wilson C, Au J, Koh CJ, Gargollo P et al (2016) Fetal lower urinary tract obstruction: proposal for standardized multidisciplinary prenatal management based on disease severity. Ultrasound Obstet Gynecol 48(4):476-482. https://doi.org/10.1002/uog.15844

22. Ruano R, Duarte S, Bunduki V, Giron AM, Srougi M, Zugaib M (2010) Fetal cystoscopy for severe lower urinary tract obstruction-initial experience of a single center. Prenat Diagn 30(1):30-39. https://doi.org/10. 1002/pd.2418

23. Ruano R, Sananes N, Sangi-Haghpeykar H, Hernandez-Ruano S, Moog R, Becmeur F et al (2015) Fetal intervention for severe lower urinary tract obstruction: a multicenter case-control study comparing fetal cystoscopy with vesicoamniotic shunting. Ultrasound in obstetrics \& gynecology : the official journal of the International Society of Ultrasound in Obstetrics and Gynecology 45(4):452-458. https://doi.org/10. 1002/uog.14652

24. Sananes N, Favre R, Koh CJ, Zaloszyc A, Braun MC, Roth DR et al (2015) Urological fistulas after fetal cystoscopic laser ablation of posterior urethral valves: surgical technical aspects. Ultrasound in obstetrics \& gynecology : the official journal of the International Society of Ultrasound in Obstetrics and Gynecology 45(2):183-189. https://doi.org/10. 1002/uog.13405

25. Quintero RA, Johnson MP, Romero R, Smith C, Arias F, Guevara-Zuloaga F et al (1995) In-utero percutaneous cystoscopy in the management of fetal lower obstructive uropathy. Lancet 346(8974):537-540. https:// doi.org/10.1016/s0140-6736(95)91381-5

26. Welsh A, Agarwal S, Kumar S, Smith RP, Fisk NM (2003) Fetal cystoscopy in the management of fetal obstructive uropathy: experience in a single European centre. Prenat Diagn 23(13):1033-1041. https://doi. org/10.1002/pd.717

27. Hennus PM, van der Heijden GJ, Bosch JL, de Jong TP, de Kort LM (2012) A systematic review on renal and bladder dysfunction after endoscopic treatment of infravesical obstruction in boys. PLoS ONE 7(9):e44663. https://doi.org/10.1371/journal.pone.00446 63PONE-D-12-12656

28. De Gennaro M, Capitanucci ML, Mosiello G, Caione P, Silveri M (2000) The changing urodynamic pattern from infancy to adolescence in boys with posterior urethral valves. BJU Int 85(9):1104-1108

29. Casey JT, Hagerty JA, Maizels M, Chaviano AH, Yerkes E, Lindgren BW et al (2012) Early administration of oxybutynin improves bladder function and clinical outcomes in newborns with posterior urethral valves. J Uro 188(4 Suppl):1516-1520. doi: S0022-5347(12)03289-2 [pii] 10.1016/j. juro.2012.03.068

30. Abdelhalim A, El-Hefnawy AS, Dawaba ME, Bazeed MA, Hafez AT (2020) Effect of Early Oxybutynin Treatment on Posterior Urethral Valve Outcomes in Infants: A Randomized Controlled Trial. J Urol 203(4):826-831. https://doi.org/10.1097/JU.0000000000000691

31. Kim YH, Horowitz M, Combs AJ, Nitti VW, Borer J, Glassberg KI (1997) Management of posterior urethral valves on the basis of urodynamic findings. J Urol 158(3 Pt 2):1011-1016

32. Puri A, Bhatnagar V, Grover VP, Agarwala S, Mitra DK (2005) Urodynamicsbased evidence for the beneficial effect of imipramine on valve bladders in children. Eur J Pediatr Surg 15(5):347-353. https://doi.org/10. 1055/s-2005-865842

33. Veenboer PW, Huisman J, Chrzan RJ, Kuijper CF, Dik P, de Kort LM et al (2013) Behavioral effects of long-term antimuscarinic use in patients with spinal dysraphism: a case control study. J Urol 190(6):2228-2232. https:// doi.org/10.1016/j.juro.2013.06.036

34. Misseri R, Combs AJ, Horowitz M, Donohoe JM, Glassberg KI. Myogenic failure in posterior urethral valve disease: real or imagined? J Urol. 
2002;168(4 Pt 2):1844-8; discussion 8. doi: https://doi.org/10.1097/01.ju. 0000029633.06239.b7.

35. Holmdahl G, Sillen U, Hanson E, Hermansson G, Hjalmas K (1996) Bladder dysfunction in boys with posterior urethral valves before and after puberty. J Urol 155(2):694-698

36. Donohoe JM, Weinstein RP, Combs AJ, Misseri R, Horowitz M, Schulsinger $D$, et al. When can persistent hydroureteronephrosis in posterior urethral valve disease be considered residual stretching? J Urol. 2004;172(2):70611; discussion 11. doi: https://doi.org/10.1097/01.ju.0000129139.10189.3f.

37. De Gennaro M, Capitanucci ML, Capozza N, Caione P, Mosiello G, Silveri M (1998) Detrusor hypocontractility in children with posterior urethral valves arises before puberty. Br J Urol 81 (Suppl 3):81-85

38. Androulakakis PA, Karamanolakis DK, Tsahouridis G, Stefanidis AA, Palaeodimos I (2005) Myogenic bladder decompensation in boys with a history of posterior urethral valves is caused by secondary bladder neck obstruction? BJU Int 96(1):140-143. https://doi.org/10.1111/j.1464-410X. 2005.05583.x

39. Combs AJ, Horowitz M, Glassberg KI (2009) Secondary bladder neck obstruction in boys with a history of posterior urethral valve: revisited. Journal of Urology, supplement 181:171

40. Abraham MK, Nasir AR, Sudarsanan B, Puzhankara R, Kedari PM, Unnithan GR et al (2009) Role of alpha adrenergic blocker in the management of posterior urethral valves. Pediatr Surg Int 25(12):1113-1115. https://doi. org/10.1007/s00383-009-2469-9

41. Dinneen MD, Duffy PG, Barratt TM, Ransley PG (1995) Persistent polyuria after posterior urethral valves. Br J Urol 75(2):236-240

42. Koff SA, Mutabagani KH, Jayanthi VR (2002) The valve bladder syndrome: pathophysiology and treatment with nocturnal bladder emptying. J Urol 167(1):291-297

43. Naghizadeh S, Kefi A, Dogan HS, Burgu B, Akdogan B, Tekgul S (2005) Effectiveness of oral desmopressin therapy in posterior urethral valve patients with polyuria and detection of factors affecting the therapy. Eur Urol 48(5):819-825. https://doi.org/10.1016/j.eururo.2005.05.019

44. Bajpai M, Chaturvedi PK, Bal CS, Sharma MC, Kalaivani M (2013) Posterior urethral valves: Persistent renin angiotensin system activation after valve ablation and role of pre-emptive therapy with angiotensin converting enzyme-inhibitors on renal recovery. J Indian Assoc Pediatr Surg 18(2):74-78. https://doi.org/10.4103/0971-9261.109357JIAPS-18-74

45. Palmer LS, Lee C, Decker RS, Lang S, Kaplan WE, Firlit CF et al (1997) The effect of angiotensin converting enzyme inhibition and angiotensin II receptor antagonism on obstructed rat bladder. J Urol 158(3 Pt 2):1100-1104. https://doi.org/10.1097/00005392-199709000-00105

46. Nguyen MT, Pavlock CL, Zderic SA, Carr MC, Canning DA. Overnight catheter drainage in children with poorly compliant bladders improves post-obstructive diuresis and urinary incontinence. J Urol. 2005;174(4 Pt 2):1633-6; discussion 6

47. Ansari MS, Srivastava A, Kapoor R, Dubey D, Mandani A, Kumar A (2008) Biofeedback therapy and home pelvic floor exercises for lower urinary tract dysfunction after posterior urethral valve ablation. J Urol 179(2):708711. https://doi.org/10.1016/j.juro.2007.09.091

48. Sarhan O, El-Ghoneimi A, Hafez A, Dawaba M, Ghali A, el Ibrahiem H (2010) Surgical complications of posterior urethral valve ablation: 20 years experience. J Pediatr Surg 45(11):2222-2226. https://doi.org/10.1016/j. jpedsurg.2010.07.003

49. Babu R, Kumar R (2013) Early outcome following diathermy versus cold knife ablation of posterior urethral valves. J Pediatr Urol 9(1):7-10. https:// doi.org/10.1016/j.jpurol.2012.02.014

50. Bhatnagar V, Agarwala S, Lal R, Mitra DK (2000) Fulguration of posterior urethral valves using the Nd:YAG laser. Pediatr Surg Int 16(1-2):69-71

51. Mandal S, Goel A, Kumar M, Singh MK, Singh V, Sankhwar SN, et al. Use of holmium:YAG laser in posterior urethral valves: another method of fulguration. J Pediatr Urol. 2013;9(6 Pt B):1093-7. doi: https://doi.org/10. 1016/j.jpurol.2013.03.015.

52. Stuhldreier G, Schweizer P, Hacker HW, Barthlen W (2001) Laser resection of posterior urethral valves. Pediatr Surg Int 17(1):16-20

53. Shukla AR. Posterior urethral valves and urethral anomalies. In: Wein AJ, Kavoussi LR, Partin AW, Peters CA, editors. Campbell-Walsh Urology. Eleventh edition ed. Philadelphia, PA.: Elsevier; 2016. p. 3252-71.

54. Liard A, Seguier-Lipszyc E, Mitrofanoff P (2000) Temporary high diversion for posterior urethral valves. J Urol 164(1):145-148
55. Ghanem MA, Nijman RJ (2005) Long-term followup of bilateral high (sober) urinary diversion in patients with posterior urethral valves and its effect on bladder function. J Urol 173(5):1721-1724. https://doi.org/10. 1097/01.ju.0000157326.62792.39

56. Close CE, Carr MC, Burns MW, Mitchell ME (1997) Lower urinary tract changes after early valve ablation in neonates and infants: is early diversion warranted? J Urol 157(3):984-988

57. Podesta M, Ruarte AC, Gargiulo C, Medel R, Castera R, Herrera M, et al. Bladder function associated with posterior urethral valves after primary valve ablation or proximal urinary diversion in children and adolescents. J Urol. 2002;168(4 Pt 2):1830-5; discussion 5. doi: https://doi.org/10.1097/ 01.ju.0000030685.14269.0a.

58. Kim YH, Horowitz M, Combs A, Nitti VW, Libretti D, Glassberg KI (1996) Comparative urodynamic findings after primary valve ablation, vesicostomy or proximal diversion. J Urol 156(2 Pt 2):673-676

59. Khoury AE, Houle AM, Mclorie GA, Churchill BM (1990) Cutaneous vesicostomy effect on bladder's eventual function. Dial Pediatr Urol 13:4-7

60. Glassberg KI (2001) The valve bladder syndrome: 20 years later. J Urol 166(4):1406-1414

61. Duckett JW (1997) Are "valve bladders" congenital or iatrogenic? Br J Urol 79(2):271-275. https://doi.org/10.1046/j.1464-410x.1997.26922.x

62. Jayanthi VR, McLorie GA, Khoury AE, Churchill BM (1995) The effect of temporary cutaneous diversion on ultimate bladder function. J Urol 154(2 Pt 2):889-892. https://doi.org/10.1097/00005392-199508000-00155

63. Farhat W, McLorie G, Capolicchio G, Khoury A, Bagli D, Merguerian PA (2000) Outcomes of primary valve ablation versus urinary tract diversion in patients with posterior urethral valves. Urology 56(4):653-657

64. Chua ME, Ming JM, Carter S, El Hout Y, Koyle MA, Noone D et al (2018) Impact of Adjuvant Urinary Diversion versus Valve Ablation Alone on Progression from Chronic to End Stage Renal Disease in Posterior Urethral Valves: A Single Institution 15-Year Time-to-Event Analysis. J Urol 199(3):824-830. https://doi.org/10.1016/j.juro.2017.10.024

65. McDonald SP, Craig JC, Australian, New Zealand Paediatric Nephrology A. Long-term survival of children with end-stage renal disease. N Engl J Med. 2004;350(26):2654-62. doi: https://doi.org/10.1056/NEJMoa031643.

66. Alexander RT, Foster BJ, Tonelli MA, Soo A, Nettel-Aguirre A, Hemmelgarn BR et al (2012) Survival and transplantation outcomes of children less than 2 years of age with end-stage renal disease. Pediatr Nephrol 27(10):1975-1983. https://doi.org/10.1007/s00467-012-2195-8

67. Bartsch L, Sarwal M, Orlandi P, Yorgin PD, Salvatierra O Jr (2002) Limited surgical interventions in children with posterior urethral valves can lead to better outcomes following renal transplantation. Pediatr Transplant 6(5):400-405

68. Kajbafzadeh AM, Payabvash S, Karimian G. The effects of bladder neck incision on urodynamic abnormalities of children with posterior urethral valves. J Urol. 2007;178(5):2142-7; discussion 7-9. doi: https://doi.org/10. 1016/j.juro.2007.07.046.

69. Singh SK, Sharma V, Singh A (2019) Urodynamic Changes after Valve Fulguration Alone and Valve Fulguration with Bladder Neck Incision. J Indian Assoc Pediatr Surg 24(1):31-35. https://doi.org/10.4103/jiaps.JIAPS_141_ 17

70. Mokhless I, Zahran AR, Saad A, Yehia M, Youssif ME (2014) Effect of Botox injection at the bladder neck in boys with bladder dysfunction after valve ablation. J Pediatr Urol. https://doi.org/10.1016/j.jpurol.2013.12.023

71. Taskinen S, Heikkila J, Rintala R (2012) Effects of posterior urethral valves on long-term bladder and sexual function. Nat Rev Urol 9(12):699-706. https://doi.org/10.1038/nrurol.2012.196

72. Keihani S, Kajbafzadeh AM, Kameli SM, Abbasioun R (2017) Long-term Impacts of Concurrent Posterior Urethral Valve Ablation and Bladder Neck Incision on Urinary Continence and Ejaculation. Urology 99:278-280. https://doi.org/10.1016/j.urology.2016.09.036

73. Hennus PML, Hoenjet E, Kieft JH, de Jong T, de Kort LMO (2017) The Long-term Effect of Superficial Bladder Neck Incision on Ejaculation and Incontinence in Boys with Primary and Secondary Bladder Neck Obstruction. Front Pediatr 5:152. https://doi.org/10.3389/fped.2017.00152

74. Alfrey EJ, Salvatierra O Jr, Tanney DC, Mak R, Scandling JD, Dafoe DC et al (1997) Bladder augmentation can be problematic with renal failure and transplantation. Pediatr Nephrol 11(6):672-675. https://doi.org/10.1007/ s004670050362 
75. Lopez Pereira P, Ortiz R, Espinosa L, Martinez Urrutia MJ, Lobato R, Alonso A et al (2014) Does bladder augmentation negatively affect renal transplant outcome in posterior urethral valve patients? J Pediatr Urol. https:// doi.org/10.1016/j.jpurol.2014.01.011

76. Youssif M, Badawy H, Saad A, Hanno A, Mokhless I (2007) Augmentation ureterocystoplasty in boys with valve bladder syndrome. J Pediatr Urol 3(6):433-437. https://doi.org/10.1016/j.jpurol.2007.06.005

77. Kajbafzadeh AM, Quinn FM, Duffy PG, Ransley PG (1995) Augmentation cystoplasty in boys with posterior urethral valves. J Urol 154(2 Pt 2):874-877

78. Landau EH, Jayanthi VR, Khoury AE, Churchill BM, Gilmour RF, Steckler RE et al (1994) Bladder augmentation: ureterocystoplasty versus ileocystoplasty. J Urol 152(2 Pt 2):716-719. https://doi.org/10.1016/s0022-5347(17) 32689-7

79. Bhatti W, Sen S, Chacko J, Thomas G, Karl S, Mathai J et al (2007) Does bladder augmentation stabilize serum creatinine in urethral valve disease? A series of 19 cases. J Pediatr Urol 3(2):122-126. https://doi.org/10 1016/j.jpurol.2006.06.004

80. Hart A, Smith JM, Skeans MA, Gustafson SK, Wilk AR, Castro S, et al. OPTN/ SRTR 2018 Annual Data Report: Kidney. American journal of transplantation : official journal of the American Society of Transplantation and the American Society of Transplant Surgeons. 2020;20 Suppl s1:20-130. doi: https://doi.org/10.1111/ajt.15672.

81. Saad IR, Habib E, EISheemy MS, Abdel-Hakim M, Sheba M, Mosleh A et al (2016) Outcomes of living donor renal transplantation in children with lower urinary tract dysfunction: a comparative retrospective study. BJU Int 118(2):320-326. https://doi.org/10.1111/bju.13347

82. Mendizabal S, Zamora I, Serrano A, Sanahuja MJ, Roman E, Dominguez C et al (2006) Renal transplantation in children with posterior urethral valves. Pediatr Nephrol 21(4):566-571. https://doi.org/10.1007/ s00467-006-0032-7

83. Otukesh H, Basiri A, Simfroosh N, Hoseini R, Fereshtehnejad SM, Chalian M (2008) Kidney transplantation in children with posterior urethral valves. Pediatr Transplant 12(5):516-519. https://doi.org/10.1111/j.1399-3046. 2007.00846.x

84. Fine MS, Smith KM, Shrivastava D, Cook ME, Shukla AR (2011) Posterior urethral valve treatments and outcomes in children receiving kidney transplants. J Urol 185(6 Suppl):2507-2511. https://doi.org/10.1016/j.juro. 2011.01.017

85. Hebenstreit D, Csaicsich D, Hebenstreit K, Muller-Sacherer T, Berlakovich G, Springer A (2018) Long-term outcome of pediatric renal transplantation in boys with posterior urethral valves. J Pediatr Surg 53(11):22562260. https://doi.org/10.1016/j.jpedsurg.2018.07.003

86. Reinberg Y, Gonzalez R, Fryd D, Mauer SM, Najarian JS (1988) The outcome of renal transplantation in children with posterior urethral valves. J Urol 140(6):1491-1493. https://doi.org/10.1016/s0022-5347(17)42082-9
87. Groenewegen AA, Sukhai RN, Nauta J, Scholtmeyer RJ, Nijman RJ (1993) Results of renal transplantation in boys treated for posterior urethral valves. J Urol 149(6):1517-1520. https://doi.org/10.1016/s0022-5347(17) 36432-7

88. Churchill BM, Sheldon CA, McLorie GA, Arbus GS (1988) Factors influencing patient and graft survival in 300 cadaveric pediatric renal transplants. J Urol 140(5 Pt 2):1129-1133. https://doi.org/10.1016/s0022-5347(17) 41979-3

89. Salomon L, Fontaine E, Gagnadoux MF, Broyer M, Beurton D (1997) Posterior urethral valves: long-term renal function consequences after transplantation. J Urol 157(3):992-995. https://doi.org/10.1016/s00225347(01)65128-0

90. DeFoor W, Tackett L, Minevich E, McEnery P, Kitchens D, Reeves D et al (2003) Successful renal transplantation in children with posterior urethral valves. J Urol 170(6 Pt 1):2402-2404. https://doi.org/10.1097/01.ju.00000 89773.40598.b3

91. Rigamonti W, Capizzi A, Zacchello G, Capizzi V, Zanon GF, Montini G et al (2005) Kidney transplantation into bladder augmentation or urinary diversion: long-term results. Transplantation 80(10):1435-1440. https:// doi.org/10.1097/01.tp.0000174342.19265.f4

92. Christman MS, Canning DA, Schast AP, Baluarte HJ, Kaplan BS (2013) Renal transplantation into a diverted urinary system-is it safe in children? I Urol 190(2):678-682. https://doi.org/10.1016/j.juro.2013.02.019

93. Viswanathan A, Leffler T, Paloian N, Cain M, McKenna PH. Early transplantation into a vesicostomy: a safe approach for managing patients with severe obstructive lesions who are not candidates for bladder augmentation. J Pediatr Urol. 2018;14(4):332 e1- e6. doi: https://doi.org/10.1016/j. jpurol.2018.07.022.

94. Fontaine E, Gagnadoux MF, Niaudet P, Broyer M, Beurton D (1998) Renal transplantation in children with augmentation cystoplasty: long-term results. J Urol 159(6):2110-2113

95. Koo HP, Bunchman TE, Flynn JT, Punch JD, Schwartz AC, Bloom DA (1999) Renal transplantation in children with severe lower urinary tract dysfunction. J Urol 161(1):240-245

96. Taghizadeh AK, Desai D, Ledermann SE, Shroff R, Marks SD, Koffman G et al (2007) Renal transplantation or bladder augmentation first? A comparison of complications and outcomes in children. BJU Int 100(6):13651370. https://doi.org/10.1111/j.1464-410X.2007.07096.x

\section{Publisher's Note}

Springer Nature remains neutral with regard to jurisdictional claims in published maps and institutional affiliations.

\section{Submit your manuscript to a SpringerOpen ${ }^{\circ}$ journal and benefit from:}

- Convenient online submission

- Rigorous peer review

- Open access: articles freely available online

- High visibility within the field

- Retaining the copyright to your article

Submit your next manuscript at $\boldsymbol{\nabla}$ springeropen.com 